\title{
Hong Kong Higher Education and its Academic Profession: ENTERING THE RED CHAMBER'
}

\section{Gerard A. Postiglione}

Gerard A. Postiglione is on the Foculfy of the School of Educotion, Universify of Hong Kong, Pokfulam Road, Hong Kong.

$\mathrm{W}$ ithin a period of less than ten years, Hong Kong has been transformed from a colonial societywith two universities serving a small elite to a transitional society with six universitiesserving a more diverse population. Hong Kong has also been much involved in the modernization of mainland China. The rapid expansion has not occured without difficulty. A decline in student ability levels, especially in language ability, has created a need for more effective teaching measures and the addition of a year' of general education at the start of the three-year university degree program. The diversity that has accompanied the expansion has led to increased demands on university administrations to operate more transparently to promote improved morale and institutional loyalty among the faculty. Moreover, whether or not they accept the challenge, Hong Kong's univenities will continue to he viewed as key institutions for the development of democratic institutions in the territory's future. While Hong Kong is not at the bottom of the international ranking in measures of academic freedom, it did not rank highly in comparison to other countries in a 1994 international study. Given the fact that Hong Kong has long touted its freedom of speech, it is surprising that it ranked below its East Asian neighbors (Japan and South Korea) on the question of whether academic freedom is strongly protected in its society?

\section{The Context \& Higher Education}

Though it ranks 90th by population, Hong Kong is the world's 8th largest trading economy. Its nearly 6 million inhabitants (98 percent Cantonese-speaking Chinese) enjoy the second-highestliving standard in Asia, freedom of speech, the rule of law, and a fully elected legislature since 1995 (which Beijing has said it will replace in 1997). Other features of Hong Kong include its large banking sector, efficient civil service, robust textile and electronicsindısmes, highly skilled and educated populace, and a unique blend of intemationalism and neo-Confucianism.

Higher education has rapidly expanded. An executive led decision to nearly double the number of students admitted to university degree studies hy 1994-95 was taken in November 1989to boost confidence and replace the emi- gration of talent following upheavals in China. Twentyfive percent of the relevant age group is in postsecondary institutons. The mean percentage of the relevant age group admitted to degree study increased to 18 percent in 1994 5 , when total enrollments reached about 58,000. An estimated 30,000 or more attend universities overseas.)

In 1997, the territory will become a Special Administrative Region of the People's Republic of China under a "one country - two systems" arrangement, in which the current education system may he maintained. Embodied in its future constitution, the Basic Law, is a high degree of autonomy and the provision that Hong Kong people will rule Hong Kong. Confidence in its future waxes and wanes depending on events in China and the state of relations between China and the United Kingdom.

The decolonization of higher education has come to mean more frequent contacts with universities in China alongside closer economic and political ties.

The decolonization of higher education has come to mean more frequent contacts with universities in China alongside closer economic and political ties, declining legitimacy of colonial educational policy, localization of the highest administrative positions, more attention to Chinese heritage, efforts to step up as well as resist the pace of democratization, increased emigration of faculty with retum migration of those who have acquired overseas passports, and expandingcultural and human resource linkages with adjacent South China-especially the Pearl River Delta?

Within the context of decolonization, higher education is confronting at least four issues. First, rapid expansion means increased competition among the seven institutions of higher education supported by the University Grants Committee, for funding, students, and faculty. This has led to the introduction of increased accountability measures, as well as the establishment of academic centers of excellence.' Second, academic freedom and institutional autonomy have become less certain as the tendency toward self-censorshipbecomes more pronounced. Third, Hong Kong's research in science and technology is not keeping pace with that of its regional rivals in Singapore, Taiwan, and South Korea. ${ }^{6}$ The final issue concerns the 
large number of overseasappointees and the fact that about 90 percent of all doctorates held by Hong Kong faculty were earned overseas, usually in Australia, Canada, the United Kingdom, or the United States. These factors are embedded within the problem of balancing localization of administration, nationalization of the university mission, localization of academic leadership, and an internationalization of university curriculum.?

\section{Higher Education Institutions, Governance, and Development}

Hong Kong has nine degree-granting institutions of higher education, including six universities, and a tertiary institution, the Academy of Performing Arts and the Open Learning Institute? All but the last of these is fully govemment funded. Before 1990, most degree courses were offered in two universities. A third university was establishedin 1991. In the meantime, the two polytechnics and two tertiary colleges began to offer degree programs. The polytechnics and one of the tertiary institutions earned university titles in 1994. Tbethree top-tier universities - the University of Hong Kong, the Chinese University of Hong Kong, and the Hong Kong University of Science and Technologyeach provide a range of programs leading to undergraduate and graduate qualifications. They offer research programs in every subject area and provide scope for faculty to undertake consultancy and collaborative projects with industry. ${ }^{9}$ The medium of instruction is English except in the Chinese University of Hong Kong, which is a bilingual institution.

The Hong Kong Polytechnic University and the City University of Hong Kong (the former polytechnics) offer a range of courses leading to the awards of diploma, higher certificate, higher diploma, and bachelor's degree. They offer a small number of graduate degrees and have research programs in some areas; emphasize the application of knowledge and vocational training; and maintain strong links with industry and employers. The Hong Kong Baptist University (formerly Baptist College) and Lingnan College together provide undergraduate courses in the arts, sciences, social sciences, business, and communicationstudies. They plan to or already offer a small number of courses at the graduate level, with research programs in some subject areas and maintaining strong links with the community.

The most influential body in higher education is the University Grants Committee (UGC). It was established in 1965 "to advise the government on the facilities, development, and financial needs of the universities." ${ }^{10}$ In 1993, the body included eight local Hong Kong Chinese, five members from the United Kingdom, three Americans (in- cluding a professor of Hong Kong Chinese origin), and one Australian. It is expected that the future UGC will include members from mainland China, especially since the governor of Hong Kong, who is thechancellor of the universities, and who appoints the members of the UGC, will be appointed by Beijing after 1997.

\section{Hong Kong's reincorporation into the People's Republic of Chinain 1997 could have major implications for its academic freedom and autonomy. The academic profession has the capacity to act as a catalyst for a smooth transition, or as a vehicle of resistance.}

\section{The Academic Profession}

Hong Kong's academicprofession has much to gain or lose in the coming years as sovereignty is returned to China. It is more closely bound to Westem university traditions and practicesthan is the case elsewhere in Asia. This gives Hong Kong the potential to influence the academic profession in China by offering a unique model of successful East-West academicintegration. In addition, given the status of intellectuals in China, Hong Kong's reincorporation into the People's Republic of China in 1997 could have major implications for its academic freedom and autonomy." The academic profession has the capacity to act as a catalyst for a smooth transition, or as a vehicle of resistance.

Over 40 percent of faculty respondents to a 1993 survey indicated they are likely to leave within five years. In order to minimize the brain drain across types of institutions, a number of measures are being implemented, including introducing parity in all aspects of salaries and benefits and across terms of appointment (local and overseas). In addition, mobility of staff between types of institutions could be encouraged by supporting a broader distribution of internationally recognized centers of academic excellence across all institutions in a variety of fields. The expansion of higher education also necessitates casting a wider net for recruitment of faculty. That net will surely include China, which will contribute more to the staffing of the universities. At present, however, mainland China has its own shortage of doctorates and doctoral programs. This has created a large market for doctoral programs overseas, something that universities in Hong Kong are also tapping into by increasing the proportion of their doctoral students from mainland China. Hong Kong insti- 
tutions of higher education have also begun to take advantage of the talents of people from mainland China who have earned doctorates in other counmes hut have not returned to China.

It is clear that the character of the academic profession in Hong Kong is changing in other ways as well. More doctorates are now earned in the United States than in the United Kingdom or other counmes. Rather than following the changingpattems in British higher education, Hong Kong has begun to draw more upon innovations from other countries as well. Of relevance in this context is the finding that those with higher degrees from the United States rate their training significantlyhigher than do those who earned higher degrees in the United Kingdom. The same holds true for the perceptions of faculty about the quality of the training they received for research.

Despite a recognition of declining academicstandards, the academic profession supports the expansion of higher education provided that there are minimum standards of admission. At the same time more than two-thirds think that higher education should not he provided free to students, and more than 80 percent say that business should make a contribution.

Hong Kong higher education faculty were asked to rank in importance for Hong Kong eight aims of higher education. The ranking, based on the relative percentage of faculty selecting each stated aim is as follows: promoting free intellectual inquiry, strengthening the society's capacity to compete internationally; promoting scholarship and research; preparing students for work; life-long learning for adults; educating students for leadership; helping to resolve basic social problems; and the preservation of the cultural heritage. The ranking of nine selected global issues in terms of the relative percentage of faculty who believe it should be assigned the highest priority hy government is as follows: basic education; environmental quality; human rights; world economy; AIDS and other health-related issues; population growth; racial, ethnic, and religious conflict; arms control; and world food supply.

The state of the Hong Kong economy in the coming years may also determine whether Hong Kong decides to increase, decrease, or maintain the degree of internationalization within the profession, especially as it finds a growing pool of talent in China and the surrounding region, where economic links are growing stronger. Other factors will he equallyimportant in the effort to maintain an international profession - factors such as working conditions, the intellectual environment, and the degree of academic freedom.
Notes

' This subtitle is taken from Dream of the Red Chamber, a classicin Chineseliterature.

2 Emest L. Boyer, Philip G. Altbach, and Mary Jean Whitelaw, The Academic Profession: An International Perspective, (Princeton, N.J.: The Carnegie Foundation for the Advancement of Teaching, 1994).

${ }^{3}$ These figures exclude mainland China and Taiwan.

${ }^{4}$ See Hong Kong Becoming China: The Transition to 1997, a series of volumes edited by Gerard A. Postiglione and Ming K. Chan. Among the volumes are Gerard A. Postiglione and Julian YM. Leung, eds., Education and Society in Hong Kong: Toward One Country and Two Systems (Armonk, N. Y:: M. E. Sharpe, 1991) also, Reginald Kwok and Alvin So, eds. The Hmg Kong-Guangdong Economic Nexus: Partnership $m$ Flux ( $h$ on $\boldsymbol{k}$, N.Y.: M. E. Sharpe, 1995).

${ }^{5}$ See Higher Education in Hmg Kmg 1995-2001: An Interim Report (Hong Kong: University and Polytechnic Grants Committee, November 1993).

${ }^{6}$ See Kin Bing Wu, Higher Education in Hmg Kmg: Investment in Science and Technology during the Time of Political and Economic Change (Washington, D.C.: World Bank, December 1992).

7 See Gerard A. Postiglione and James T.H. Tang, eds., Hong Kong in the World Community: Internationalization at Risk? ( h o n k, N.Y: M.E. Sharpe, forthcoming).

8 Hugh Witt, ed., Hmg Kong Yearbook 1993: A Review o 1992 (Hong Kong: Government Printer, 1993). The six universities and tertiary college are funded through the University Grants Committee, while the Academy of Performing Arts is funded by the Recreation and Culture Branch of the government. Hong Kong also has a post-secondary institution, Shue Yan College, which is privately funded.

${ }^{9}$ See University and Polytechnic Grants Committee Secretariat statement of October 1992, entitled "HigherEducationin Hong Kong," Ref: UPGC/GEN/222/90.

10 University Grants Committee of Hmg Kmg: Facts and Figures (Hong Kong: University Grants Committee Secretariat, 1995).

11 See for example, Merle Goldman, with Timothy Cheek and Carol Lee Hamrin, eds., China's Intellectuals and the State: In Search of a NEw Relationship, Harvard Contemporary China Series: 3, The Council on East Asian Studies (Cambridge: Harvard University Press, 1987)also, Richard Madsen, "The Spiritual Crisis of China's Intellectuals," in Deborah Davis and E m Vogel, Chinese Society a the Eve of Tiananmen: The Impact of Reform, Harvard ContemporaryChina Series 7, The Council of East Asian Studies, (Cambridge: Harvard University Press, 1990); and Merle Goldman, "The Intellectuals in the Deng Xiaoping Era," in Arthur Lewis Rosenbaum, ed., State and Society in China:The Consequences of Reform (Boulder, Colo.: Westview Press, 1992). 